\title{
Septal Glucagon-Like Peptide I Receptor Expression Determines Suppression of Cocaine-Induced Behavior
}

\author{
Anne E Harasta', John M Power', Georg von Jonquieres', Tim Karl2,3, Daniel J Drucker ${ }^{4}$, Gary D Housley', \\ Miriam Schneider ${ }^{5,6}$ and Matthias Klugmann*,1,6 \\ 'Translational Neuroscience Facility and Department of Physiology, School of Medical Sciences, UNSW Australia, Sydney, NSW, Australia; \\ ${ }^{2}$ Neuroscience Research Australia, Randwick, NSW, Australia; ${ }^{3}$ School of Medical Sciences, UNSW Australia, Sydney, NSW, Australia; ${ }^{4}$ Department \\ of Medicine, Samuel Lunenfeld Research Institute, Mount Sinai Hospital, University of Toronto, Toronto, ON, Canada; ${ }^{5}$ Research Group \\ Developmental Neuropsychopharmacology, Institute of Psychopharmacology, Central Institute of Mental Health, Medical Faculty Mannheim, \\ Heidelberg University, Mannheim, Germany
}

\begin{abstract}
Glucagon-like peptide I (GLP-I) and its receptor GLP-IR are a key component of the satiety signaling system, and long-acting GLP-I analogs have been approved for the treatment of type-2 diabetes mellitus. Previous reports demonstrate that GLP-I regulates glucose homeostasis alongside the rewarding effects of food. Both palatable food and illicit drugs activate brain reward circuitries, and pharmacological studies suggest that central nervous system GLP-I signaling holds potential for the treatment of addiction. However, the role of endogenous GLP-I in the attenuation of reward-oriented behavior, and the essential domains of the mesolimbic system mediating these beneficial effects, are largely unknown. We hypothesized that the central regions of highest Glp-Ir gene activity are essential in mediating responses to drugs of abuse. Here, we show that $G|p-| r$-deficient $\left(G \mid p-I r^{-1-}\right)$ mice have greatly augmented cocaine-induced locomotor responses and enhanced conditional place preference compared with wild-type $\left(G \mid p-l r^{+/+}\right.$) controls. Employing mRNA in situ hybridization we located peak Glp-Ir mRNA expression in GABAergic neurons of the dorsal lateral septum, an anatomical site with a crucial function in reward perception. Whole-cell patch-clamp recordings of dorsal lateral septum neurons revealed that genetic Glp-Ir ablation leads to increased excitability of these cells. Viral vector-mediated Glp-Ir gene delivery to the dorsal lateral septum of $G \mid p-1 r^{-l-}$ animals reduced cocaine-induced locomotion and conditional place preference to wild-type levels. This site-specific genetic complementation did not affect the anxiogenic phenotype observed in Glp- Ir ${ }^{-1-}$ controls. These data reveal a novel role of GLP-IR in dorsal lateral septum function driving behavioral responses to cocaine.

Neuropsychopharmacology (2015) 40, 1969-1978; doi:I0.1038/npp.20I5.47; published online 4 March 2015
\end{abstract}

\section{INTRODUCTION}

The shift from controlled to compulsive drug use leading to addiction is poorly understood but seems to involve pathways originally evolved for natural rewards like food (Volkow and Wise, 2005). Recent preclinical studies suggested that glucagon-like peptide 1 (GLP-1) modulates the rewarding effects of both food (Alhadeff et al, 2012; Dickson et al, 2012; Dossat et al, 2011) and addictive drugs (Egecioglu et al, 2013a, b, 2013c; Erreger et al, 2012; Graham et al, 2013). This was supported by the observation that pretreatment with the synthetic GLP-1R agonist Exendin-4 (Ex4) attenuates the behavioral effects of drugs of abuse including ethanol (Egecioglu et al, 2013c; Shirazi et al, 2013), nicotine (Egecioglu et al, 2013a), amphetamine, and cocaine

\footnotetext{
*Correspondence: Professor M Klugmann, Translational Neuroscience Facility and Department of Physiology, School of Medical Sciences, UNSW Australia, Wallace Wurth Building, Randwick, Sydney, NSW 2052. Australia, Tel: +6I 29385 I056, Fax: +6I (0)29 385 I485, E-mail: m.klugmann@unsw.edu.au

${ }^{6}$ The last two authors contributed equally to this work.

Received 21 November 2014; revised 21 lanuary 2015; accepted 5 February 20 I5; accepted article preview online II February 2015
}

(Egecioglu et al, 2013a, b; Erreger et al, 2012; Graham et al, 2013). Therefore, GLP-1R agonists have been proposed as treatment options for drug addiction. Most studies employed the systemic administration of GLP-1R ligands, obviating the dissection of peripheral versus central GLP-1R effects. Interestingly, GLP-1R activation in the ventral tegmental area (VTA) mediates the rewarding effects of alcohol (Shirazi et al, 2013) and palatable food (Mietlicki-Baase et al, 2013). In addition, systemic Ex4 decreases the release of dopamine in the nucleus accumbens (NAc) (Egecioglu et al, 2013a, b). It remains to be determined whether these effects are because of a direct activation of GLP-1R in the NAc and VTA or rather a result of modulations on a circuit level.

In the central nervous system (CNS), GLP-1 is produced by neurons in the nucleus of the solitary tract (NTS) that project to various regions, including sites that regulate stress responses, as well as reward and motivation (LlewellynSmith et al, 2011; Rinaman, 2010). The immunohistochemical detection of GLP-1R expression in the brain is unknown as specific anti-GLP-1R antibodies are not available (Pyke and Knudsen, 2013), yet ligand binding assays suggest the presence of the receptor in the amygdala and the mesolimbic 
system, including the VTA, NAc, and lateral septum (LS), providing an anatomical correlate for the reported beneficial effects of pharmacological GLP-1R stimulation (Göke et al, 1995).

The LS is highly interconnected with the mesolimbic system (Olds and Milner, 1954; Sheehan, 2004) primarily through $\gamma$-aminobutyric acid (GABA)ergic projections (Gallagher et al, 1995; Risold and Swanson, 1997a). LS neurons form a strong collateral network (Gallagher et al, 1995; Sheehan, 2004) that not only causes recurrent inhibition within the LS, but also tightly controls the activity of extraseptal target areas (Sheehan, 2004). The LS regulates responses to natural rewards (Noda et al, 1997) and is involved in stress-induced relapse to drug abuse (Highfield et al, 2000). Hence, the LS is a hub that integrates information arriving from central key regulators and mediates appropriate behavioral responses (Sheehan, 2004). A recent study identified a novel circuit, linking context and reward, that relies on neurons of the dorsal LS (dLS) (Luo et al, 2011). This circuit starts with hippocampal glutamatergic projections that stimulate GABAergic neurons in the dLS. These dLS neurons project to the VTA, leading to disinhibition of dopaminergic neurons within the VTA, and a subsequent increase of dopamine levels in the NAc (Luo et al, 2011; Mazei-Robison et al, 2011).

The identification of mechanisms that regulate LS activity is therefore important for understanding the circuits of the mesolimbic reward system as well as the neurobiology of druginduced neuroplasticity and drug reinforcement. Here, we used a genetic mouse model with a targeted null mutation of the Glp-1r locus (Scrocchi et al, 1996), enabling the determination of behavioral responses to cocaine administration that were dependent upon GLP-1-mediated LS neuromodulation.

\section{MATERIALS AND METHODS}

\section{Animals}

Experiments were carried out in accordance with the UNSW Australia Animal Care and Ethics Committee. Heterozygous Glp-1 $1 r^{+/-}$breeding pairs were used to produce age-matched male Glp-1r ${ }^{-/-}$mice (Scrocchi et al, 1996) on C57BL/6J background and Glp-1r ${ }^{+/+}$littermates. PCR genotyping was performed as described previously (Kim et al, 2013). Animals were individually housed in a temperature- and humiditycontrolled room with a $12 \mathrm{~h}$ light/dark cycle and had access to food and water ad libitum.

\section{Adeno-Associated Virus (AAV) Constructs}

The rat Glp-1r open reading frame was cloned upstream and in-frame with the coding region of the enhanced green fluorescent protein (GFP) reporter in an AAV expression cassette containing the $1.1-\mathrm{kb}$ chicken $\beta$-actin promoter (CBA), the woodchuck hepatitis virus posttranscriptional regulatory element (WPRE), and the bovine growth hormone polyadenylation sequence (bGHpA) flanked by AAV2 inverted terminal repeats (pAAV-GLP-1R-GFP). The same backbone carrying no Glp-1r cDNA was used as a control (pAAV-GFP). In addition, a nontagged GLP-1R construct (During et al, 2003) was used as a control for experiments in human embryonic kidney (HEK293) cells.

\section{Immunoblotting}

HEK293 cells were transfected with pAAV-GLP-1R-GFP, pAAV-GLP-1R, or pAAV-GFP, using the standard calcium phosphate $\left(\mathrm{CaPO}_{4}\right)$ precipitation method. At $48 \mathrm{~h}$ after transfection, the cells were exposed to Ex4 $(10 \mathrm{nM})$ for 0$50 \mathrm{~min}$ before harvesting in solubilization buffer ( $30 \mathrm{mM}$ Tris$\mathrm{Cl}, \mathrm{pH} 7.4$, and $5 \mathrm{mM} \mathrm{MgCl} 2$ containing $4 \mathrm{mg}$ of CHAPS (Sigma) and $20 \%$ glycerol). Then, $10 \mu \mathrm{g}$ of total protein was resolved by $12 \%$ SDS-PAGE and electroblotted onto nitrocellulose membrane. The membrane was incubated with primary antibodies against phosphorylated extracellular signal-regulated kinases (mouse anti-pERK1/2; 1:2500; Cell Signaling, Danvers, MA) and the GFP-tag (rabbit anti-GFP; $1: 2000$ (von Jonquieres et al, 2013)). The membrane was reprobed using a rabbit anti-ERK1/2 antibody $(1: 2500$; Cell Signaling). Secondary antibodies were horseradish peroxidase conjugated as required (1:5000; Dianova, Hamburg, Germany). Immunoreactivity was detected using the enhanced chemiluminescence system (Bio-Rad, Gladesville, NSW, Australia) and digitalized (GelDoc, Bio-Rad).

\section{AAV Vector Generation and Administration}

Packaging of neurotropic AAVrh10 vectors was performed as described previously (Klugmann et al, 2005). Briefly, following triple transfection of HEK293 cells, AAV vectors were purified using iodixanol (OptiPrep, Sigma-Aldrich, Taufkirchen, Germany) gradient ultracentrifugation (Zolotukhin et al, 2002). Titers were determined by quantitative real-time PCR of vector genomes using primers for WPRE. Then, $1 \mu \mathrm{l}$ of either AAV-GLP-1R-GFP or AAV-GFP $\left(8 \times 10^{11} \mathrm{vg} / \mathrm{ml}\right)$ was injected bilaterally into the dLS $(+0.5 \mathrm{~mm}$ AP, $\pm 0.3 \mathrm{~mm}$ $\mathrm{ML},-2.6 \mathrm{~mm}$ DV from bregma). Vectors were delivered to 4 week-old mice at a rate of $150 \mathrm{nl} / \mathrm{min}$ using a microprocessor-controlled mini-pump (World Precision Instruments, Sarasota, FA) with $34 \mathrm{G}$ beveled needles (World Precision Instruments) in a stereotaxic frame (Kopf Instruments, Tujunga, CA).

\section{Immunohistochemistry}

Brains of all animals were assessed for transgene expression at the end of behavioral testing. Immunostaining of brain sections was performed as previously described (Klugmann et al, 2005). Briefly, mice were transcardially perfused with $10 \%$ buffered neutral formalin (Sigma-Aldrich), removed, and post-fixed for $2 \mathrm{~h}$ in the same fixative before cryoprotection in $30 \%$ sucrose/PBS. Free-floating cryosections $(40 \mu \mathrm{m})$ were rinsed with PBS-Triton X-100 (0.2\%), blocked in immunobuffer (4\% horse serum in PBS, $\mathrm{pH}$ 7.4, 0.4\% Triton $\mathrm{X}-100$ ), followed by incubation with rabbit anti-GFP (von Jonquieres et al, 2013) $(1: 1000)$. Sections were then incubated with donkey anti-rabbit Alexa 488 antibody $(1: 1000$; Invitrogen, Karlsruhe, Germany) and counterstained with 4',6-diamidino-2-phenylindole (DAPI). Sections were mounted and coverslipped with Mowiol (Sigma-Aldrich). Fluorescence was visualized using a confocal microscope (Zeiss Z1 AxioExaminer NLO710; Carl Zeiss, North Ryde, NSW, Australia). 


\section{In Situ Hybridization (ISH)}

ISH was performed as previously described (Marsicano and Lutz, 1999). Both digoxygenin (DIG)-labeled and fluorescein isothiocyanate (FITC)-labeled riboprobes were used as described elsewhere (Yang et al, 1999). The cDNAs encoding glutamic acid decarboxylase (GAD65) and mouse GLP-1R (GenBank accession number: NM_021332) in the pBlueskript plasmid backbone, including a Glp-1r sense probe, were used for in vitro transcription. Hybridization was carried out overnight at $55^{\circ} \mathrm{C}$ in $100 \mu \mathrm{l}$ of buffer containing DIG-labeled (300 ng/ml) Glp- $1 r$ riboprobe for single ISH or, in case of double ISH, additional FITC-labeled Gad65 riboprobe $(300 \mathrm{ng} / \mathrm{ml})$. Sections were counterstained with DAPI or toluidin blue and coverslipped in Mowiol or DPX (Sigma-Aldrich). Fluorescent sections were visualized using a confocal microscope; DIG-labeled sections were visualized using an Olympus BX51 microscope. Semiquantitative analysis, in the coronal plane cut through bregma, was performed by determining the number of Glp-1r mRNAexpressing cells among the total population of dLS neurons identified by soma size or Gad65 mRNA-expressing neurons. Samples were collected from three Glp-1r $r^{-/-}$and $G l p-1 r^{+/+}$ animals (three sections per animal, spaced $80 \mu \mathrm{m}$ ). Digitalized images were processed with Adobe Photoshop CS5 or ZEN lite (Zeiss) where appropriate.

\section{Electrophysiology}

Coronal brain slices $(300 \mu \mathrm{m})$ were prepared from mice (4-8 weeks) using a VT1200 vibratome (Leica) according to standard techniques (Power and Sah, 2007). Briefly, mice were anesthetized with isoflurane (5\%) and decapitated, and the brains removed and sectioned in oxygenated $\left(95 \% \mathrm{O}_{2}\right.$, $5 \% \mathrm{CO}_{2}$ ) ice-cold, modified artificial cerebrospinal fluid (ACSF) containing the following (in $\mathrm{mM}$ ): $125 \mathrm{NaCl}, 3 \mathrm{KCl}$, $1.25 \mathrm{NaH}_{2} \mathrm{PO}_{4}, 25 \mathrm{NaHCO}_{3}, 6 \mathrm{MgCl}_{2}, 1 \mathrm{CaCl}_{2}$, and 10 glucose. Slices were incubated at $34{ }^{\circ} \mathrm{C}$ for $30 \mathrm{~min}$ and thereafter maintained at room temperature in ACSF solution (in mM): $125 \mathrm{NaCl}, 3 \mathrm{KCl}, 1.25 \mathrm{NaH}_{2} \mathrm{PO}_{4}, 25 \mathrm{NaHCO}_{3}, 1$ $\mathrm{MgCl}_{2}, 2 \mathrm{CaCl}_{2}$, and 25 glucose (equilibrated with $95 \% \mathrm{O}_{2}$, $5 \% \mathrm{CO}_{2}$ ). Whole-cell patch-clamp recordings were made from visually identified neurons (Zeiss Axio Examiner D1) in slices continuously superfused with ACSF $(1-2 \mathrm{ml} / \mathrm{min})$ heated to $30 \pm 1^{\circ} \mathrm{C}$ using an in-line heater (TC-324B Warner Instrument Corporation). Patch pipettes (2-4M $\Omega$ ) were filled with internal solution (in mM): $135 \mathrm{KMeSO}_{4}, 7 \mathrm{NaCl}$, 10 HEPES, $2 \mathrm{Mg}_{2} \mathrm{ATP}$, and $0.3 \mathrm{Na}_{3} \mathrm{GTP}$, pH 7.3 with $\mathrm{KOH}$ (osmolarity, $280-300 \mathrm{mOsm} / \mathrm{kg}$ ). Electrophysiological recordings utilized an Axopatch 200B amplifier (Molecular Devices), filtered at $2-5 \mathrm{kHz}$, digitized at $20 \mathrm{kHz}$ with a Digidata1440 (Molecular Devices) interface, controlled using PClamp 10.2 software (Molecular Devices). Current was injected to adjust the membrane potential to $-65 \mathrm{mV}$, and the voltage response to somatic current injections $(600 \mathrm{~ms}$, -50 to $+150 \mathrm{pA}, 10 \mathrm{pA}$ increments) was used to measure the neuron's AP firing pattern. Action potential latency was calculated from the first action potential evoked at the threshold current injection. Neurons with resting potentials $>-55 \mathrm{mV}$ were excluded from the data set. Voltage-clamp was employed to dissect dLS membrane conductances, in particular A-type $\mathrm{K}^{+}$-currents (Supplementary Data).

\section{Behavioral Testing}

All animals were adult (2-4 months) and individually housed 2 weeks before behavioral testing to prevent abnormal behavior caused by fighting or suppression by the alpha male. Experience in our lab shows that reward-related behavior does not change in C57bl6/J mice between 2 and 6 months. All animals were subjected to the following battery of tests. The elevated plus maze (EPM) was employed to assess inherent anxiety-related behavior. The maze consisted of two opposite open arms and two opposite enclosed arms, interconnected by a central platform (center $6 \times 6 \mathrm{~cm}^{2}$; open arms, $35 \times 6 \mathrm{~cm}^{2}$; closed arms, $35 \times 6 \times 15 \mathrm{~cm}^{3}$; elevation $1 \mathrm{~m}$; illumination $40 \mathrm{lux})$. Mice were placed on the maze, facing a closed arm and were allowed to freely explore the EPM for $5 \mathrm{~min}$. Mouse behavior was analyzed using ANY-maze tracking software (Stoelting, Wood Dale, IL). The ratio of time spent in open arms was used to estimate open arm aversion (reflecting anxiety). The same cohorts of animals were subjected to two noncontingent models of substance abuse (Kalivas, 2009). Briefly, clear Plexiglas boxes $(41 \times 41 \times 40 \mathrm{~cm}$; Photobeam Activity System: MedAssociates, St Albans, VT) were used as open field boxes for recording the locomotor sensitization to cocaine (30 min sessions per test day). After an initial day with saline injections (baseline activity), animals received cocaine $(10 \mathrm{mg} / \mathrm{kg}$, IP) for 5 consecutive days (days 1-5; with day 5 representing the development of sensitization). After 7 consecutive drug- and testfree days, all mice received a priming injection of cocaine (day 12; representing the expression of sensitization). The last day of sensitization was followed by 14 test-free days before the same animals were subjected to the conditioned place preference (CPP) test. CPP was evaluated using a modified unbiased protocol as described previously (Bilbao et al, 2008). Briefly, CPP was performed in a custom-made box with two equally sized compartments $(25 \times 25 \times 40 \mathrm{~cm})$ interconnected by a rectangular corridor. The compartments were differentiated by the pattern of the walls and texture of the floor. Mice received one session of preconditioning $(15 \mathrm{~min})$, followed by 4 days of conditioning. During the conditioning phase, mice were treated with eight alternating injections of saline (morning) and cocaine $(10 \mathrm{mg} / \mathrm{kg}$; IP; afternoon) and then confined to the corresponding compartment immediately after the injection for $30 \mathrm{~min}$. For the postconditioning test (performed at noon), mice were allowed to explore the apparatus without any treatment for $15 \mathrm{~min}$. The CPP score represents the difference between the time spent in the cocaine compartment before and following conditioning.

\section{Data Analysis and Statistics}

Current clamp data were analyzed off-line using custom routines written in LabVIEW (National Instruments, Austin, TX). Data are presented as means \pm SEM and were analyzed as appropriate using unpaired, two-tailed $t$-test, or two-way repeated measures ANOVA followed by the Bonferroni post hoc test to evaluate statistical significance. In all cases, $P<0.05$ was considered statistically significant.

\section{RESULTS}

\section{Abundant Expression of Endogenous Glp-1r in the LS}

Glp-1r-expressing cells were found in the amygdala as well as the hypothalamus (Figure 1a). In order to gain an overview 

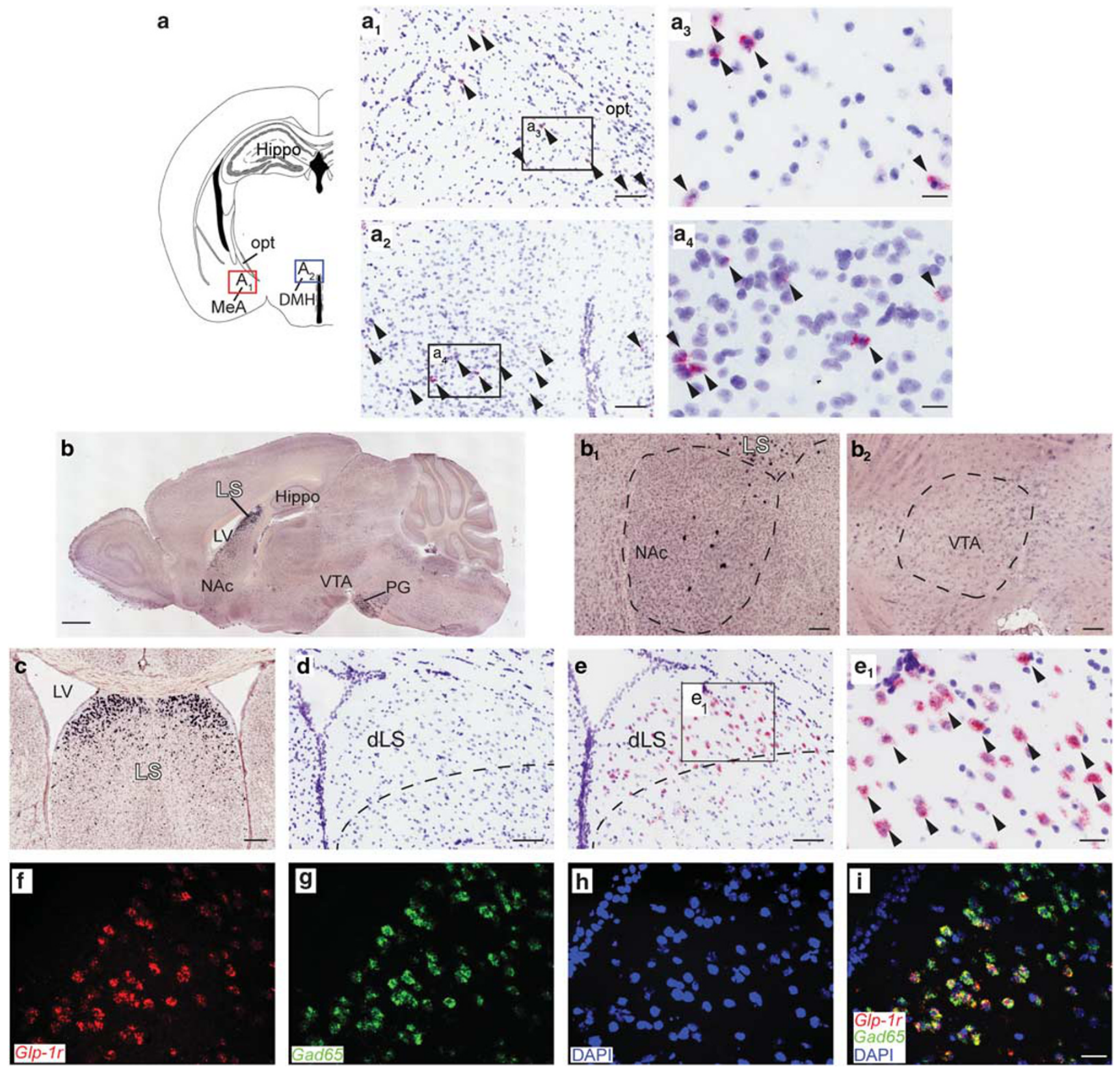

Figure I Glp-Ir mRNA is enriched in the lateral septum. (a) Illustration of a coronal mouse brain section. ( $a_{1}, a_{2}$ ) Glp-I r mRNA-expressing cells (purple) in the medial amygdaloid nucleus (red box in (a)) or the hypothalamus (blue box in (a)) labeled by arrowheads. ( $a_{3}$, $a_{4}$ ) High magnification of individual Glp-Ir mRNA-positive cells. (b) Overview of Glp-Ir mRNA expression (black staining) domains in the sagittal plane (Allen Brain Atlas ID 73606497_I25). (b।, b2) Close-ups of the NAc and the VTA showing little Glp-I r expression. (c) In the coronal plane, highest Glp-Ir expression (silver impregnation) was identified in the LS (Allen Brain Atlas ID 745 I I 737_345). (d) The Glp-Ir sense probe produced no signal. (e) Abundant Glp-Ir mRNA expression (pink) was confirmed in the dLS using a specific DIG-labeled riboprobe. $\left(e_{1}\right)$ Higher magnification of the dLS indicated by the box in (e) depicting strong cellular signal detection of GlpIr mRNA. (f) Fluorescent detection of Glp-Ir (red) and (g) Gad65 (green) mRNA in the dLS. (h) Nuclear counterstaining with DAPI (blue). (i) Merged picture reveals that almost all GIp-Ir-positive septal neurons are GABAergic. Bars: (a $\left.a_{1}, a_{2}, d, e\right) 75 \mu \mathrm{m} ;\left(a_{3}, a_{4}, e, f\right) 10 \mu \mathrm{m} ;(b)$ I mm; (bl, b2) $100 \mu \mathrm{m}$; (c) $200 \mu \mathrm{m}$. dLS, dorsal lateral septum; DMH, dorsomedial hypothalamic nucleus; Hippo, hippocampus; LV, lateral ventricle; MeA, medial amygdaloid nucleus; NAc, nucleus accumbens; opt, optic tract; PG, pontine gray; VTA, ventral tegmental area.

of Glp-1r gene activity, we utilized expression data publicly available from the Allen Brain Atlas database (Lein et al, 2007). High-density Glp-1r mRNA labeling was detected not only in the pontine gray but also in the LS (Figure 1b). In contrast, only few or no Glp-1R-positive cells were found in the NAc (Figure $1 b_{1}$ ) or VTA (Figure $1 b_{2}$ ). Given that LS neurons project to both areas, we further elucidated Glp-1r mRNA expression in the LS. Abundant Glp-1r expression levels in the LS were corroborated assessing an independent Allen Brain Atlas data set (Figure 1c). We then performed ISH to identify Glp-1r expression in the LS in more detail. Hybridization with the sense riboprobe did not result in 
signal detection, confirming absence of nonspecific signals (Figure 1d). The antisense riboprobe confirmed strong Glp-1r mRNA expression in the dLS as shown in a representative image (Figure 1e). Semiquantitation of these results revealed that $>95 \%$ of dLS neurons express Glp-1r mRNA. To identify the phenotype of Glp-1r-positive dLS neurons, we performed double fluorescent ISH using probes for $G l p-1 r$ and Gad65, the enzyme responsible for GABA synthesis. Virtually all Glp-1r-positive cells expressed Gad65, indicating that these cells are inhibitory GABAergic neurons (Figures 1f-i). No signal was detected with the antisense probe using brain sections from GLP-1R-deficient mice (not shown).

\section{Ablation of GLP-1R Signaling Alters Intrinsic Excitability of Septal Neurons}

Our anatomical data suggested that septal GLP-1Rs may play an important role in the mesolimbic reward system. We hypothesized that this is caused by GLP-1R-dependent changes in dLS neuronal excitability and therefore analyzed the firing properties of $G l p-1 r^{+/+}$and $G l p-1 r^{-/-}$neurons employing brain slice whole-cell patch-clamp. The dLS neurons from Glp-1r $r^{+/+}$and $G l p-1 r^{-7-}$ did not differ in their passive membrane properties (resting potential, input resistance, membrane time constant) or their AP waveform (threshold, amplitude, width), their fast AHP amplitude, or the minimum current required to elicit an AP (Supplementary Table S1). However, there were differences in the neuronal firing properties. In response to a threshold current injection, the onset of the AP was delayed in $G l p-1 r^{-1-}$ neurons compared with $G l p-1 r^{+/+}$controls (Figure 2a). Increasing the injected current revealed that septal Glp-1r $r^{-/-}$ neurons were more excitable, firing more APs than $G l p-1 r^{+/+}$ neurons to twice threshold current injections (Figure 2d) and to current injections $>120 \mathrm{pA}$ (Figure $2 \mathrm{e}$ and $\mathrm{f}$ ). The AP onset difference suggested that fast activating voltage-dependent $\mathrm{K}^{+}$ currents might be altered in $G l p-1 r^{-/-}$neurons. Dissecting these currents with voltage-clamp protocols in combination with the pharmacological blockage isolated prominent A-type $\mathrm{K}^{+}$ currents that were retained with Glp-1r deletion (Supplementary Figure S1).

\section{GLP-1R in the dLS Controls Cocaine-Induced Behaviors}

Our anatomical and electrophysiological data indicated that GLP-1R contributes to dLS function and therefore to behavioral outputs modulated by the dLS (Sheehan, 2004). We hypothesized that assessments of anxiety-related and drug-induced behaviors would reveal deficits in $G l p-1 r^{-/-}$ mice that were tied to the dLS and hence could be rescued by genetic complementation of GLP-1R in the dLS.

To achieve precise anatomical accuracy for expression of transgenic GLP-1R in vivo, we employed the AAV platform to induce robust long-term transgene expression following intracranial delivery (Klugmann et al, 2005). The AAV expression construct included a GFP-epitope tag at the GLP-1R C-terminus for immunodetection of the recombinant receptor (Figure 3a). Biological functionality of the tagged receptor was confirmed in heterologous HEK293 cells by monitoring the activation of ERK1/2, a known downstream event of GLP-1R signaling (During et al, 2003). Levels
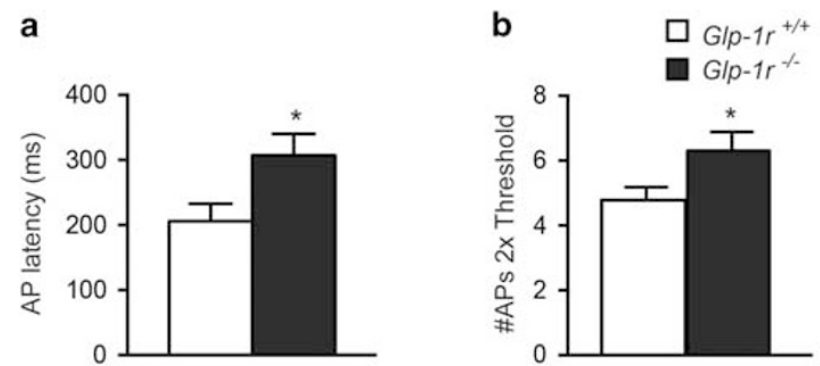

C
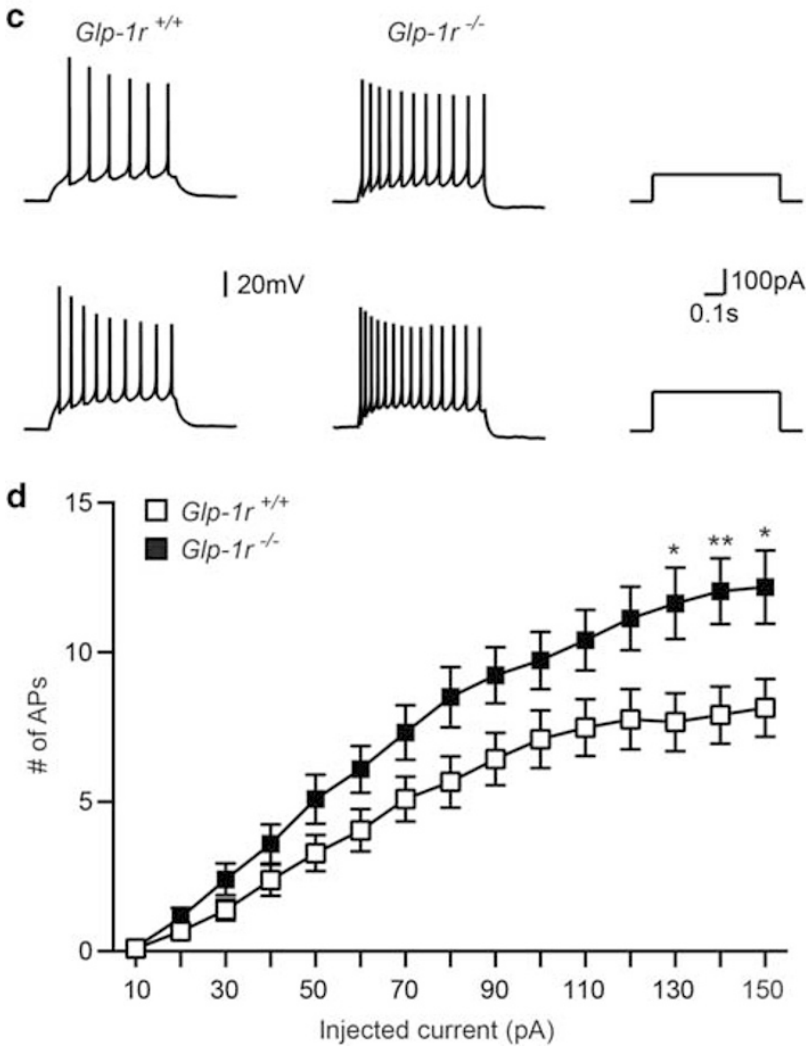

Figure 2 Increased firing of Glp- $\mid r^{-1-}$ septal neurons. (a) The time to fire an AP is delayed in Glp- $/ r^{-1-}$ (total of 23 cells from 10 animals) compared with Glp- $\mid r^{+/+}$(total of 2 I cells from I I animals) neurons $(P=0.02)$. (b) The number of APs at twice threshold was elevated in Glp-Ir ${ }^{-1-}$ compared with Glp- $\mid r^{+/+}$controls $(P=0.04)$. (c) Representative responses of $G \mid p-I r^{+/+}$(left) and Glp-Ir $r^{-1-}$ (right) neuron, respectively, to $600 \mathrm{~ms}$ depolarizing current steps at 100 and 150 pA. (d) Responses (number of APs evoked by 600 ms stimulus) of Glp- $/ r^{+/+}$and $G \mid p-I r^{-1-}$ cells across a range of step current injections from 10 to $150 \mathrm{pA}$ revealed an increased activity of $\mathrm{Glp}-1 \mathrm{r}^{-1-}$ neurons (two-way repeated measures ANOVA $\times$ genotype effect: $F(I, 43)=6.48, P=0.01)$. $* P<0.05$, ** $P<0.01$.

of phosphorylated ERK1/2 peaked at $10 \mathrm{~min}$ and declined after $20 \mathrm{~min}$ following administration of Ex4 (Figure 3b). A doublet at 80 and $100 \mathrm{kD}$ detected by immunoblot (Figure 3b) indicated posttranslational modifications. Immunocytochemical detection of recombinant GLP-1R revealed cell surface localization (Figure $3 \mathrm{c}$ ). These data suggest that the presence of the GFP tag does not interfere with receptor signaling, posttranslational processing, or trafficking.

We then packaged AAV-GLP-1R-GFP or AAV-GFP for bilateral delivery into the mouse dLS. Immunohistochemical 
a

\begin{tabular}{|l|l|l|l|l|l|}
\hline ITR & CBA & GLP-1R & WPRE & PA & ITR \\
\hline
\end{tabular}

\begin{tabular}{|l|l|l|l|l|l|}
\hline ITR & CBA & GLP-1R-GFP & WPRE & PA & ITR \\
\hline
\end{tabular}

\begin{tabular}{|l|l|l|l|l|l|}
\hline ITR & CBA & GFP & WPRE & PA & ITR \\
\hline
\end{tabular}

C

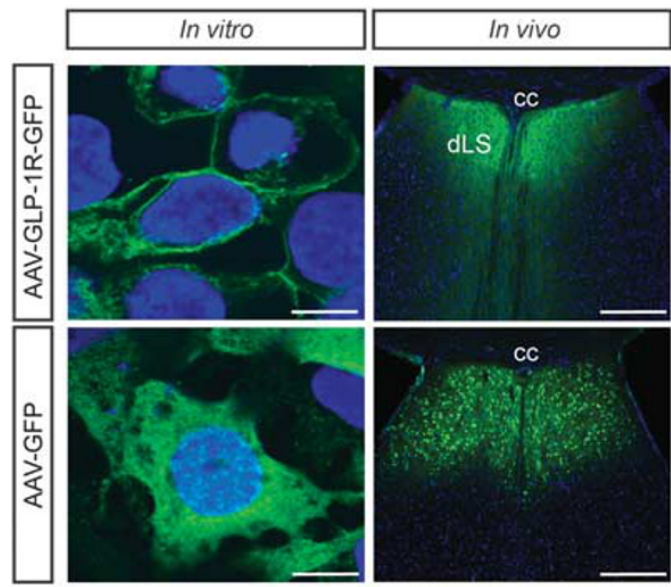

b
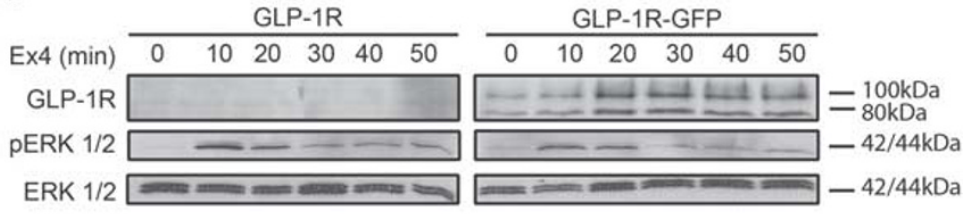

d

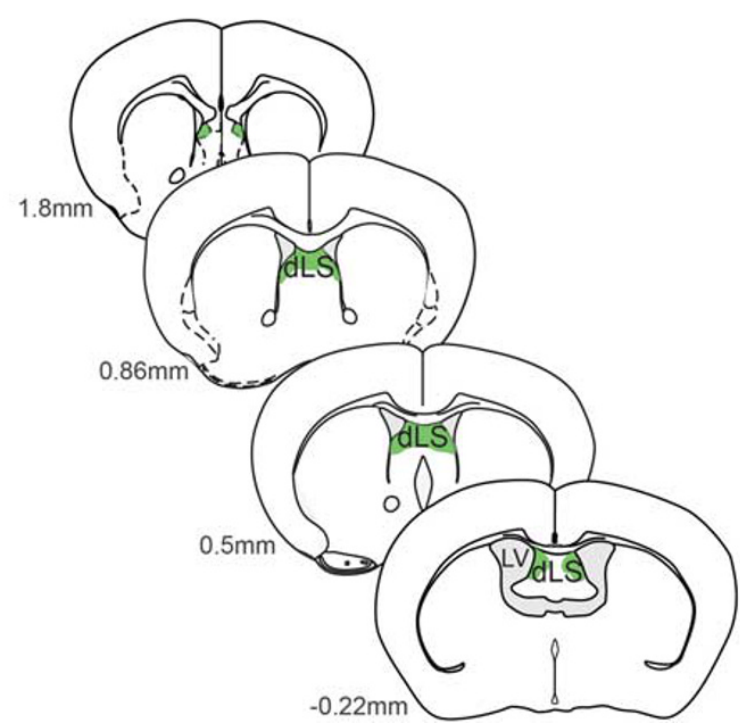

Figure $3 \mathrm{AAV}$-mediated Glp-Ir gene delivery to the dLS. (a) AAV expression cassettes. ITR, inverted terminal repeat; CBA, chicken $\beta$-actin promoter; pA, polyadenylation signal; WPRE, woodchuck hepatitis virus posttranscriptional regulatory element. (b) Biological activity of GLP-IR-GFP was confirmed by expression in heterologous HEK293 cells and exposure to Ex4 (I0 nM) for the indicated durations (0-50 min). The dynamics of ERK phosphorylation were similar following activation of the tagged GLP-IR or the native receptor. Total ERK served as loading control. Note that the GFP antibody exclusively recognized the tagged recombinant receptor. (c) Recombinant GLP-IR-GFP traffics to the cell surface in HEK293 cells and in the mouse LS (top row), whereas GFP controls show cytosolic expression (bottom row). Anti-GFP immunofluorescence (green); DAPI (blue) nuclear counterstain. Bars: I0 $\mu$ m. (d) Schematic illustration of vector spread assessed by AAV-transduced neuronal somata; cc, corpus callosum; dLS, dorsal lateral septum; LV, lateral ventricle.

assessment of transduction was performed 3 weeks following vector delivery, when AAV-mediated transgene expression is known to reach maximum and stable levels (Klugmann et al, 2005), to confirm accurate anatomical targeting; the subcellular expression patterns matched our observations in vitro (Figure $3 \mathrm{c}$ ). As anatomical confinement of the rescue experiment is essential, we investigated the possibility of offtargeting in the lateral ventricles. Transduced ependymal cells, glia lining the walls of the ventricles, are an inevitable consequence of intraventricular AAV delivery. We critically examined all 15 AAV animals $(n=9$ for AAV-GLP-1R; $n=6$ for AAV-GFP) for this feature and observed GFP-positive ependymal cells in only one case, an AAV-GFP brain, as depicted in Figure 3c.

The vector spread extended $2 \mathrm{~mm}$ in the rostrocaudal dimension (Supplementary Figure S2) and is illustrated in Figure 3d. AAVrh10 can be transported retrogradely along axonal projections (Cearley and Wolfe, 2007); except a small number of transduced CA3 pyramidal neurons in the dorsal hippocampus (not shown), we did not detect GFP-positive cell bodies in extraseptal regions.

For behavioral assessment we tested AAV-GFP-treated and naive Glp-1r $r^{-1-}$ or Glp-1r $r^{+/+}$mice. Data of the corresponding AAV-GFP and naive mice were pooled as they were not statistically different (not shown). A separate cohort entailed $G l p-1 r^{-/}$mice bilaterally injected with AAVGLP-1R-GFP into the dLS. We employed the EPM test to determine levels of inherent anxiety. Glp-1r $r^{-1-}$ mice and Glp-1r $r^{-1-}$ mice injected with AAV-GLP-1R-GFP spent less time in the center of the maze, showed fewer open arm entries, and spent less time in the open arms compared with Glp- $1 r^{+/+}$controls (Figure 4a). All groups displayed comparable locomotor activity (Supplementary Figure S3A). These results suggest that the loss of GLP-1R in brain regions outside the dLS mediate anxiety-related behavior.

The same cohorts were then subjected to the locomotor sensitization test as described (see Materials and Methods).

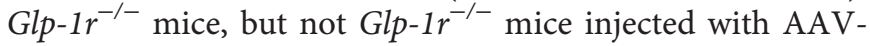
GLP-1R-GFP, showed an augmented acute response to cocaine (Figure $4 \mathrm{~b}$; day 1 ). Increased locomotor activity was detected in $G l p-1 r^{+/+}$controls and $G l p-1 r^{-/-}$mice between days 1 and 5, indicating intact development of sensitization. Although development was absent in Glp-1r $r^{-/-}$ mice injected with AAV-GLP-1R-GFP, this group was not statistically different to $G l p-1 r^{+/+}$controls. Following a drugfree period of 7 days, the animals received a cocaine

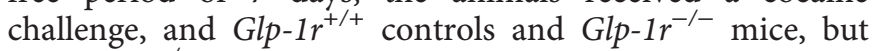
not $G l p-1 r^{-1-}$ mice injected with AAV-GLP-1R-GFP, showed expression of sensitization (day 12). Baseline locomotion in the open field box was not different among groups 
a
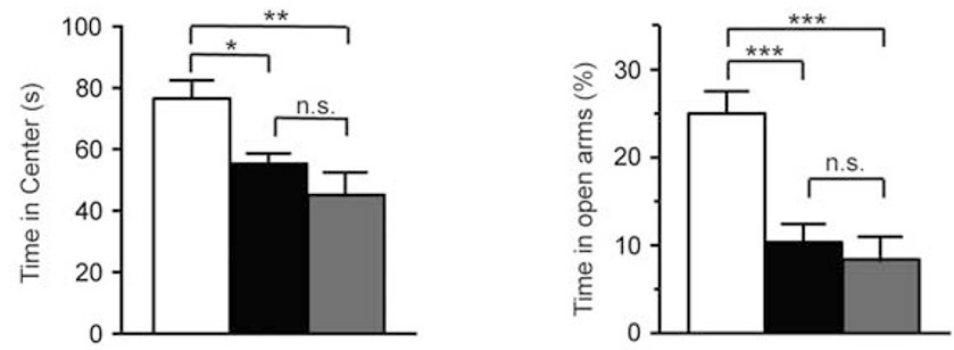

b

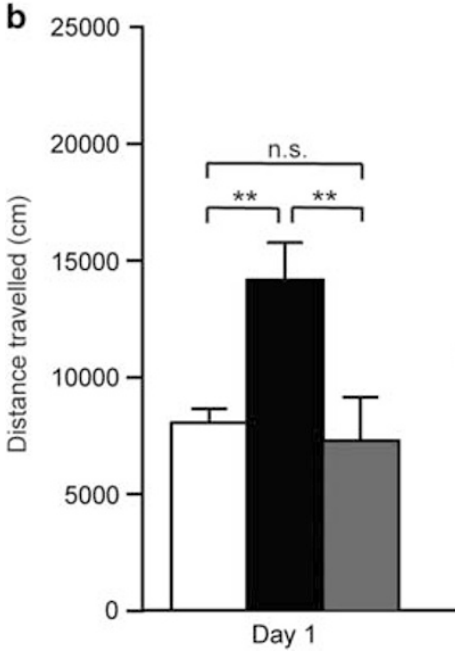

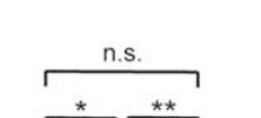
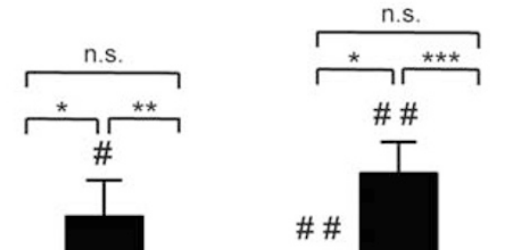

\# \#
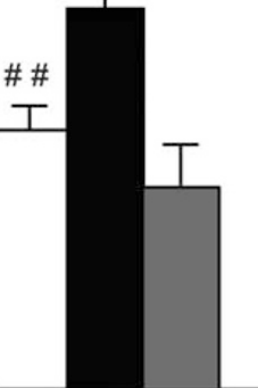

Day 5 $\square G l p-1 r^{+/+}$

Glp-1r $1-$

G Glp-1r ${ }^{\circ}+$ AAV-GLP-1R-GFP

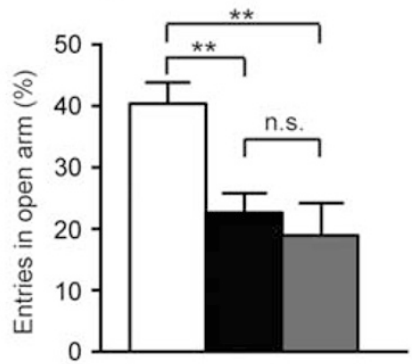

c

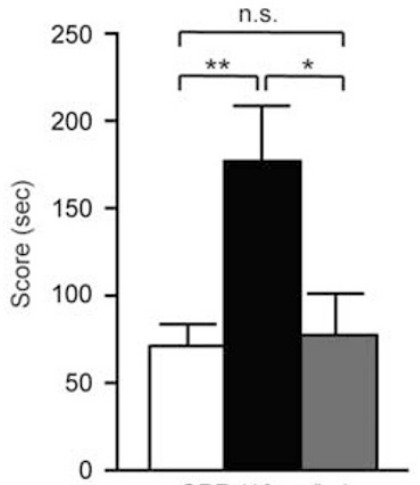

Figure 4 Genetic complementation of GLP-IR expression in the dLS rescues cocaine-induced, but not anxiety-related, behaviors in Glp- $r$-deficient mice. (a) Glp- $\mid r^{-1-}$ mice and Glp- $\mid r^{-1-}$ mice injected with AAV-GLP-IR-GFP spent less time in the center of the EPM (left panel, one-way ANOVA F=8.049; $P=0.0012) ; G \mid p-1 r^{+1+}$ controls $(n=17)$ compared with $G \mid p-1 r^{-1-}$ mice $(n=15 ; P<0.05)$, or Glp- $\mid r^{+/+}$controls compared with Glp-Ir $r^{-l-}+$ AAV-GLP-IR-GFP $(n=9 ; P<0.01)$. Middle panel: Glp-Ir $r^{-1-}$ mice and Glp-Ir $r^{-l-}$ mice injected with AAV-GLP-IR-GFP spent less time in the open arms (one-way ANOVA $F=14.34 ; P<0.000 I$ ) compared with $G \mid p-I r^{+/+}$controls $(P<0.000 I)$ and entered the open arms less frequently (right panel; one-way ANOVA $F=9.65$; $P<0.00 \mathrm{I}$; post hoc test $P<0.0 \mathrm{I}$ ). (b) Altered locomotor response to cocaine for all groups over the course of the paradigm (two-way repeated measures ANOVA genotype effect $F(2,4 \mid)=9.77 I, P=0.0003)$. There was no difference between genetically complemented $G / p-\mid r^{-1-}$ mice $(n=9)$ and $G l p-I r^{+/+}$ controls $(n=17)$ following acute cocaine exposure (day I; $P>0.9999$ ). Intact development and expression of cocaine sensitization (two-way repeated measures ANOVA cocaine effect $F(2,82)=21.00, P<0.000 I)$ was present in $G|p-| r^{+/+}$and $G|p-| r^{-1-}$ mice $(n=\mid 5)$ but absent in Glp-|r $r^{-1-}+A A V-G L P-\mid R-$ GFP mice (day I-day 5,P=0.5I4I and day I-day I2, $P=0.29 \mid 9$ ). Note that there was no difference between $G \mid p-I r^{+/+}$controls and $G \mid p-I r^{-l-}+A A V-$ GLP-IR-GFP on any given day. ${ }^{*} P$ compared with day I; $* P$ compared with all groups on a given day. (c) Genetically complemented Glp- $\mid r^{-1-}$ mice displayed a normal CPP phenotype (one-way ANOVA $F=7.037, P=0.0023$. The CPP score represents the difference between the time spent in the cocaine compartment before and following conditioning. ${ }^{*}$ or ${ }^{\#} P<0.05$, *** or ${ }^{\# \#} P<0.01$, ${ }^{*} * * P<0.001$.

(Supplementary Figure S3B). All groups showed a similar magnitude of change upon comparison of the difference between days 5 and 1 or between days 12 and 1 (Supplementary Figure S4A). Therefore, the sensitization process per se was not enhanced in Glp-1r ${ }^{-/-}$mice compared with $G l p-1 r^{+/+}$controls, probably because of the augmented initial sensitivity to cocaine and a ceiling effect in Glp-1r $r^{-1-}$ mice. Sensitization as well as initial responsiveness to psychomotor stimulants can be exhibited by stereotypy that is usually associated with a drop in locomotion. However, no alterations between groups were observed when comparing stereotypic time over the course of the experiment (Supplementary Figure S4B).

The rewarding effects of cocaine were investigated in the CPP paradigm. Glp-1r $r^{-1-}$ mice exhibited enhanced CPP compared with $G l p-1 r^{+/+}$controls following conditioning using cocaine doses of $10 \mathrm{mg} / \mathrm{kg}$ (Figure $4 \mathrm{c}$ ) or $15 \mathrm{mg} / \mathrm{kg}$ (Supplementary Figure S5), suggesting augmented cocaineseeking behavior. This response was restored in $G l p-1 r^{-1-}$ mice treated with AAV-GLP-1R-GFP (Figure 4c). To rule out that the observed CPP of Glp-1r $1 r^{-/}$mice is caused by an enhanced conditioned locomotor effect (Huston et al, 2013) we analyzed the locomotor activity during CPP expression and detected no difference between groups (Supplementary Figure S6).

Glp-1r mRNA expression was increased by fourfold in the dLS of AAV-GLP-1R-GFP-treated $G l p-1 r^{-1-}$ mutants compared with AAV-GFP-treated Glp-1 $r^{+/+}$mice using qRT-PCR analysis of brain slice punches (Supplementary Figure S7). Although the corresponding GLP-1R protein quantities could not be determined, it was shown previously that even substantial AAV-mediated transgene expression at 
mRNA levels translates to physiological protein amounts (Blume et al, 2013).

\section{DISCUSSION}

This study provides clear evidence that GLP-1R-positive dLS GABAergic neurons are critical for the mediation of druginduced behavior. Several reports have shown that feedingrelated peptides, such as leptin or ghrelin, influence the mesolimbic system (Hommel et al, 2006; Skibicka et al, 2011). The role of GLP-1 and its analogs in this context has only recently been investigated by pharmacological studies, supporting the concept that GLP-1R signaling alters behaviors induced by drugs of abuse (Egecioglu et al, 2013a, b, 2013c; Erreger et al, 2012; Graham et al, 2013; Shirazi et al, 2013). The preclinical potential of GLP-1-based compounds for the treatment of dependence has been broadly appreciated (Skibicka, 2013), and the translational relevance of this research is emerging (van Bloemendaal et al, 2014).

Acute injections of GLP-1 or Ex4 into the VTA or NAc reduce reward-driven behavior, an effect that was attributed to GLP-1R activation in these brain areas (Dickson et al, 2012; Dossat et al, 2011). The direct action of GLP-1 appears conceivable in light of classical ligand binding data reporting the presence of GLP-1R in these areas (Göke et al, 1995). Moreover, GLP-1-producing NTS neurons project into key areas of the mesolimbic system including the VTA and NAc (Merchenthaler et al, 1999; Rinaman, 2010). However, only mRNA ISH data inform specifically on the neuroanatomical sites of Glp-1r-producing neurons; whereas sparse Glp-1r mRNA levels were reported in the aforementioned parts of the mesolimbic system (Merchenthaler et al, 1999), this study identified most abundant central Glp-1r mRNA expression in the dLS (Figure $1 b$ and $c$ ), the functional relevance of which has not been appreciated yet. Broadly, the LS is connected with brain regions implicated in regulating mood and reward (Risold and Swanson, 1997b) and strongly influences motivated behaviors (Olds and Milner, 1954; Prado-Alcala et al, 1984).

Here, we utilized genetic GLP-1R models on the C57BL/6J background and showed that the complete ablation of GLP-1R caused an anxiogenic phenotype that was not restored by dLS directed AAV-Glp-1r gene delivery, suggesting that extra septal GLP-1Rs (ie, amygdala) mediate anxiety-related behavior. Inconclusive results have previously been reported for EPM test performance of GLP-1R-deficient mice on a CD1 background (MacLusky, 2000). Considering strain differences, that are known to play a critical role in mediating behavioral responses, CD1 mice showed an decrease in anxietyrelated behavior compared with the C57BL/6J background (Michalikova et al, 2010).

Glp-1r $r^{-1-}$ mice showed augmented cocaine-induced acute locomotor response and increased CPP, indicating enhanced reinforcement and stimulatory effects of cocaine in these animals. This phenotype was corrected by the genetic rescue confined to the dLS, indicating that GLP-1R in neurons from that brain region is essential for motivated behavior.

The peripheral delivery of Ex4 in mice and rats reduces cocaine and amphetamine-induced hyperlocomotion (Egecioglu et al, 2013b; Erreger et al, 2012; Graham et al,
2013); yet these pharmacological studies utilized protocols limited to monitor acute psychostimulant responses. In contrast, we employed an established sensitization paradigm testing both acute and chronic responses (Bilbao et al, 2008), revealing that complete GLP-1R ablation enhanced cocaineinduced locomotor activity throughout the test. As such, our findings are in line with the previously reported ability of Ex4 to block the expression of nicotine-induced locomotor sensitization (Egecioglu et al, 2013a). The persistent nature of the sensitized motor response has been proposed to reflect neurochemical alteration similar to the enduring changes associated with addiction, indicating potentially shared neuronal substrates (Kalivas, 2009; Robinson and Berridge, 1993).

The LS is crucial for performance in the CPP paradigm (Sartor and Aston-Jones, 2012) and our anatomical and behavioral data strongly suggest that dLS GLP-1Rs contribute to this phenomenon. Although GLP-1R-deficiency is implicated in diminished hippocampus-dependent learning (During et al, 2003), and the CPP paradigm relies on contextual memory (Cunningham et al, 2006), we detected increased cocaine-induced conditioning of $G l p-1 r^{-/-}$animals providing evidence that the contextual impairment does not confound the interpretation of the CPP performance. Given that human addiction involves drug self-administration, future experiments could employ contingent models to examine the role of septal GLP-1Rs.

The neurochemical phenotype of GLP-1R-expressing neurons is broadly unknown for most brain regions. We provide evidence that GLP-1R-positive cells in the dLS are predominantly GABAergic and it is known that LS projections terminate in the VTA and NAc (Onteniente et al, 1987; Risold and Swanson, 1997b; Swanson, 1982). Attenuated dopamine release in the NAc was reported following systemic Ex4 administration (Egecioglu et al, 2013a, c). Moreover, intra-VTA GLP-1R activation is mediated in part by nonglutamatergic mechanisms (Mietlicki-Baase et al, 2013). These data raise the possibility that the effects mediated by direct activation of GLP-1R in the mesolimbic system can be attributed to modulations on a circuit level. We propose that GLP-1R neurons in the dLS are essential for mesolimbic function. The underlying mechanisms are unclear but may involve downstream effects of GLP-1R signal transduction such as the modulation of cAMP levels (Drucker et al, 1987), activation of $\mathrm{Ca}^{2+}$-channels (AcunaGoycolea and van den Pol, 2004), or regulation of transcription factors (Klugmann et al, 2006).

In summary, we show that the dLS has the most prominent GLP-1 receptor expression in the brain. GLP-1R-null mice exhibited increased excitability in GABAergic dorsal lateral septum neurons. These mutants had strongly augmented behavioral responses to cocaine when tested in two widely used noncontingent models of drug abuse. In a rescue experiment, we genetically complemented GLP-1R expression exclusively in the dLS of GLP-1R-deficient mice and observed restoration of cocaine-induced behavior to wild-type levels. This dLS-directed rescue of the increased cocaine-induced behavioral measures in GLP-1R-null mice indicates that GLP-1 transmission in this brain region is a key suppressor of addictive drug-induced behavior. These findings will shift attention to this brain region and GLP-1 transmission as a novel target for therapeutic intervention in drug addiction. 


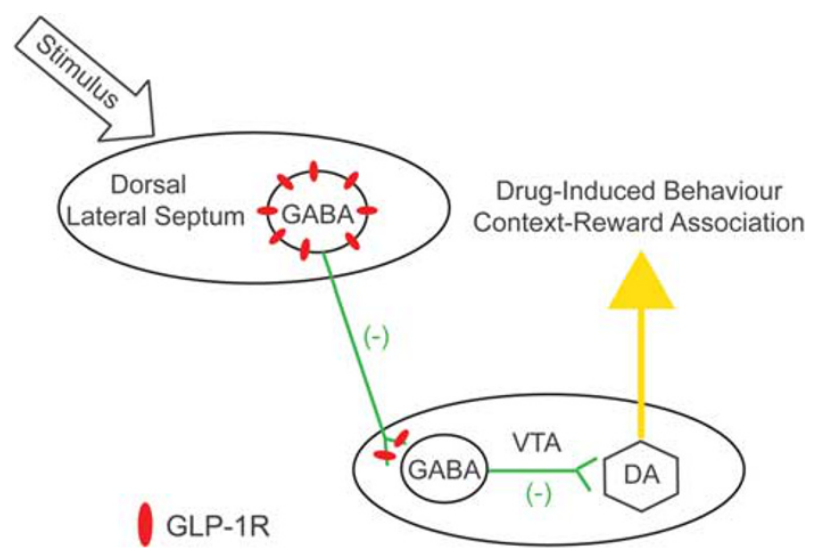

Figure 5 Septal GLP-IR regulates motivated behavior. GLP-IRexpressing GABAergic septal neurons modulate cellular activity following stimulation. GLP-IRs are present in both somata and terminals of these neurons (Göke et al, 1995; Shirazi et al, 20 I3) that form inhibitory synapses with GABAergic interneurons in the VTA (Luo et al, 20I I). Their inhibition, in turn, leads to activation of dopaminergic VTA neurons via disinhibition. Hence, this dLS-VTA pathway controls drug-induced behaviors such as locomotor sensitization and drug seeking. DA, dopamine. Adapted from Luo et al (20I I).

Our working model (Figure 5) integrates our findings into a recently proposed CA3-dLS-VTA pathway that connects dLS activity to dopamine release from VTA neurons and, in turn, modulates motivated behavior (Luo et al, 2011). Most GABAergic dLS neurons coexpress Glp-1r mRNA (Figure 1). LS cells get activated by a range of stimuli (Sheehan, 2004), leading to context-dependent (Luo et al, 2011) and druginduced adaptions of motivated behavior. GLP-1R appears to play an essential role for these adaptations, suggested by our electrophysiological (Figure 2) and genetic rescue data (Figure $4 \mathrm{~b}$ and $\mathrm{c}$ ).

\section{FUNDING AND DISCLOSURE}

DJD has served as an advisor or consultant within the past 12 months to Arisaph Pharmaceuticals, Intarcia Therapeutics, Merck Research Laboratories, MedImmune, Novo Nordisk, NPS Pharmaceuticals, Receptos, Sanofi, and Transition Pharmaceuticals. Neither Dr Drucker or his family members hold stock directly or indirectly in any of these companies. The authors declare no conflict of interest.

\section{ACKNOWLEDGMENTS}

We thank Beat Lutz for the GAD65 cDNA, Margaret Morris for critically reading the manuscript, and Claudia Klugmann for technical assistance. This work was supported by an Australian Research Council Future Fellowship to MK, and a UNSW Australia Gold Star Award to MK and GDH. AEH was supported by an UNSW Australia International PostGraduate Research Scholarship. DJD was supported in part by a Canada Research Chair in Regulatory Peptides, a Canada Research Chair in Regulatory Peptides in Incretin Biology, and operating grant 123391 from the Canadian Institutes of Health Research. TK was supported by the
Schizophrenia Research Institute utilizing infrastructure funding from NSW Ministry of Health and a career development award from the National Health and Medical Research Council.

\section{REFERENCES}

Acuna-Goycolea C, van den Pol A (2004). Glucagon-like peptide 1 excites hypocretin/orexin neurons by direct and indirect mechanisms: implications for viscera-mediated arousal. J Neurosci 24: 8141-8152.

Alhadeff AL, Rupprecht LE, Hayes MR (2012). GLP-1 neurons in the nucleus of the solitary tract project directly to the ventral tegmental area and nucleus accumbens to control for food intake. Endocrinology 153: 647-658.

Bilbao A, Parkitna JR, Engblom D, Perreau-Lenz S, Sanchis-Segura C, Schneider $\mathrm{M}$ et al (2008). Loss of the Ca2+/calmodulin-dependent protein kinase type IV in dopaminoceptive neurons enhances behavioral effects of cocaine. Proc Natl Acad Sci USA 105: 17549-17554.

Blume LC, Bass CE, Childers SR, Dalton GD, Roberts DC, Richardson JM et al (2013). Striatal CB1 and D2 receptors regulate expression of each other, CRIP1A and delta opioid systems. J Neurochem 124: 808-820.

Cearley CN, Wolfe JH (2007). A single injection of an adenoassociated virus vector into nuclei with divergent connections results in widespread vector distribution in the brain and global correction of a neurogenetic disease. J Neurosci 27: 9928-9940.

Cunningham CL, Patel P, Milner L (2006). Spatial location is critical for conditioning place preference with visual but not tactile stimuli. Behav Neurosci 120: 1115-1132.

Dickson SL, Shirazi RH, Hansson C, Bergquist F, Nissbrandt H, Skibicka KP (2012). The glucagon-like peptide 1 (GLP-1) analogue, exendin-4, decreases the rewarding value of food: a new role for mesolimbic GLP-1 receptors. J Neurosci 32: 4812-4820.

Dossat AM, Lilly N, Kay K, Williams DL (2011). Glucagon-like peptide 1 receptors in nucleus accumbens affect food intake. J Neurosci 31: 14453-14457.

Drucker DJ, Philippe J, Mojsov S, Chick WL, Habener JF (1987). Glucagon-like peptide I stimulates insulin gene expression and increases cyclic AMP levels in a rat islet cell line. Proc Natl Acad Sci USA 84: 3434-3438.

During MJ, Cao L, Zuzga DS, Francis JS, Fitzsimons HL, Jiao X et al (2003). Glucagon-like peptide-1 receptor is involved in learning and neuroprotection. Nat Med 9: 1173-1179.

Egecioglu E, Engel JA, Jerlhag E (2013a). The glucagon-like peptide 1 analogue Exendin-4 attenuates the nicotine-induced locomotor stimulation, accumbal dopamine release, conditioned place preference as well as the expression of locomotor sensitization in mice. PLoS One 8: e77284.

Egecioglu E, Engel JA, Jerlhag E (2013b). The glucagon-like peptide 1 analogue, exendin-4, attenuates the rewarding properties of psychostimulant drugs in mice. PLoS One 8: e69010.

Egecioglu E, Steensland P, Fredriksson I, Feltmann K, Engel JA, Jerlhag E (2013c). The glucagon-like peptide 1 analogue Exendin4 attenuates alcohol mediated behaviors in rodents. Psychoneuroendocrinology 38: 1259-1270.

Erreger K, Davis AR, Poe AM, Greig NH, Stanwood GD, Galli A (2012). Exendin-4 decreases amphetamine-induced locomotor activity. Physiol Behav 106: 574-578.

Gallagher JP, Zheng F, Hasuo H, Shinnick-Gallagher P (1995). Activities of neurons within the rat dorsolateral septal nucleus (DLSN). Prog Neurobiol 45: 373-395.

Göke RL, Larsen PJ, Mikkelesen JD, Sheikh SP (1995). Distribution of GLP-1 binding sites in the rat brain- evidence that exendin-4 is a ligand of brain GLP-1 binding sites. Eur J Neurosci 7: 2294-2300. 
Graham DL, Erreger K, Galli A, Stanwood GD (2013). GLP-1 analog attenuates cocaine reward. Mol Psychiatry 18: 961-962.

Highfield D, Clements A, Shalev U, McDonald R, Featherstone R, Stewart J et al (2000). Involvement of the medial septum in stressinduced relapse to heroin seeking in rats. Eur J Neurosci 12: 1705-1713.

Hommel JD, Trinko R, Sears RM, Georgescu D, Liu ZW, Gao XB et al (2006). Leptin receptor signaling in midbrain dopamine neurons regulates feeding. Neuron 51: 801-810.

Huston JP, Silva MA, Topic B, Muller CP (2013). What's conditioned in conditioned place preference? Trends Pharmacol Sci 34: 162-166.

Kalivas PW (2009). The glutamate homeostasis hypothesis of addiction. Nat Rev Neurosci 10: 561-572.

Kim M, Platt MJ, Shibasaki T, Quaggin SE, Backx PH, Seino S et al (2013). GLP-1 receptor activation and Epac2 link atrial natriuretic peptide secretion to control of blood pressure. Nat Med 19: 567-575.

Klugmann M, Leichtlein CB, Symes CW, Klaussner BC, Brooks AI, Young D et al (2006). A novel role of circadian transcription factor DBP in hippocampal plasticity. Mol Cell Neurosci 31: 303-314.

Klugmann M, Leichtlein CB, Symes CW, Serikawa T, Young D, During MJ (2005). Restoration of aspartoacylase activity in CNS neurons does not ameliorate motor deficits and demyelination in a model of Canavan disease. Mol Ther 11: 745-753.

Lein ES, Hawrylycz MJ, Ao N, Ayres M, Bensinger A, Bernard A et al (2007). Genome-wide atlas of gene expression in the adult mouse brain. Nature 445: 168-176.

Llewellyn-Smith IJ, Reimann F, Gribble FM, Trapp S (2011). Preproglucagon neurons project widely to autonomic control areas in the mouse brain. Neuroscience 180: 111-121.

Luo AH, Tahsili-Fahadan P, Wise RA, Lupica CR, Aston-Jones G (2011). Linking context with reward: a functional circuit from hippocampal CA3 to ventral tegmental area. Science 333: 353-357.

MacLusky NJ (2000). Neuroendocrine Function and Response to Stress in Mice with Complete Disruption of Glucagon-Like Peptide-1 Receptor Signaling. Endocrinology 141: 752-762.

Marsicano G, Lutz B (1999). Expression of the cannabinoid receptor $\mathrm{CB} 1$ in distinct neuronal subpopulations in the adult mouse forebrain. Eur J Neurosci 11: 4213-4225.

Mazei-Robison MS, Koo JW, Friedman AK, Lansink CS, Robison AJ, Vinish $M$ et al (2011). Role for mTOR signaling and neuronal activity in morphine-induced adaptations in ventral tegmental area dopamine neurons. Neuron 72: 977-990.

Merchenthaler IL, Lane M, Shughrue P (1999). Distribution of prepro-glucagon and glucagon-like peptide-1 receptor messenger RNAs in the rat central nervous system. Comp Neurol 403: 261-280.

Michalikova S, van Rensburg R, Chazot PL, Ennaceur A (2010). Anxiety responses in Balb/c, c57 and CD-1 mice exposed to a novel open space test. Behav Brain Res 207: 402-417.

Mietlicki-Baase EG, Ortinski PI, Rupprecht LE, Olivos DR, Alhadeff AL, Pierce RC et al (2013). The food intake-suppressive effects of glucagon-like peptide-1 receptor signaling in the ventral tegmental area are mediated by AMPA/kainate receptors. Am J Physiol Endocrinol Metab 305: E1367-E1374.

Noda Y, Mamiya T, Furukawa H, Nabeshima T (1997). Effects of antidepressants on phencyclidine-induced enhancement of immobility in a forced swimming test in mice. Eur J Pharmacol 324: 135-140.
Olds J, Milner P (1954). Positive reinforcement produced by electrical stimulation of septal area and other regions of rat brain. J Comp Physiol Psychol 47: 419-427.

Onteniente B, Geffard M, Campistron G, Calas A (1987). An ultrastructural study of GABA-immunoreactive neurons and terminals in the septum of the rat. J Neurosci 7: 48-54.

Power JM, Sah P (2007). Distribution of IP3-mediated calcium responses and their role in nuclear signalling in rat basolateral amygdala neurons. J Physiol 580: 835-857.

Prado-Alcala R, Streather A, Wise RA (1984). Brain stimulation reward and dopamine terminal fields. II. Septal and cortical projections. Brain Res 301: 209-219.

Pyke C, Knudsen LB (2013). The glucagon-like peptide-1 receptoror not? Endocrinology 154: 4-8.

Rinaman L (2010). Ascending projections from the caudal visceral nucleus of the solitary tract to brain regions involved in food intake and energy expenditure. Brain Res 1350: 18-34.

Risold PY, Swanson LW (1997a). Chemoarchitecture of the rat lateral septal nucleus. Brain Res Brain Res Rev 24: 91-113.

Risold PY, Swanson LW (1997b). Connections of the rat lateral septal complex. Brain Res Brain Res Rev 24: 115-195.

Robinson TE, Berridge KC (1993). The neural basis of drug craving: an incentive-sensitization theory of addiction. Brain Res Brain Res Rev 18: 247-291.

Sartor GC, Aston-Jones GS (2012). A septal-hypothalamic pathway drives orexin neurons, which is necessary for conditioned cocaine preference. J Neurosci 32: 4623-4631.

Scrocchi LA, Brown TJ, MaClusky N, Brubaker PL, Auerbach AB, Joyner AL et al (1996). Glucose intolerance but normal satiety in mice with a null mutation in the glucagon-like peptide 1 receptor gene. Nat Med 2: 1254-1258.

Sheehan T (2004). Regulation of affect by the lateral septum: implications for neuropsychiatry. Brain Res Rev 46: 71-117.

Shirazi RH, Dickson SL, Skibicka KP (2013). Gut peptide GLP-1 and its analogue, Exendin-4, decrease alcohol intake and reward. PLoS One 8: e61965.

Skibicka KP (2013). The central GLP-1: implications for food and drug reward. Front Neurosci 7: 181.

Skibicka KP, Hansson C, Alvarez-Crespo M, Friberg PA, Dickson SL (2011). Ghrelin directly targets the ventral tegmental area to increase food motivation. Neuroscience 180: 129-137.

Swanson LW (1982). The projections of the ventral tegmental area and adjacent regions: a combined fluorescent retrograde tracer and immunofluorescence study in the rat. Brain Res Bull 9: 321-353.

van Bloemendaal L, IJzerman RG, Ten Kulve JS, Barkhof F, Konrad RJ, Drent ML et al (2014). GLP-1 receptor activation modulates appetite- and reward-related brain areas in humans. Diabetes 63: 4186-4196.

Volkow ND, Wise RA (2005). How can drug addiction help us understand obesity? Nat Neurosci 8: 555-560.

von Jonquieres G, Mersmann N, Klugmann CB, Harasta AE, Lutz B, Teahan O et al (2013). Glial promoter selectivity following AAVdelivery to the immature brain. PLoS One 8: e65646.

Yang H, Wanner IB, Roper SD, Chaudhari N (1999). An optimized method for in situ hybridization with signal amplification that allows the detection of rare mRNAs. J Histochem Cytochem 47: 431-446.

Zolotukhin S, Potter M, Zolotukhin I, Sakai Y, Loiler S, Fraites TJ Jr. et al (2002). Production and purification of serotype 1, 2, and 5 recombinant adeno-associated viral vectors. Methods 28: $158-167$.

Supplementary Information accompanies the paper on the Neuropsychopharmacology website (http://www.nature.com/npp) 